\title{
Supercritical Carbon Dioxide Debinding in Metal Injection Molding (MIM) Process
}

\author{
Yong-Ho Kim, Youn-Woo Lee, Jong-Ku Park*, Chang-Ha Lee** and Jong Sung Lim \\ National Research Lab. for Supercritical Fluid, *Ceramic Processing Center, \\ Korea Institute of Science and Technology, P.O. Box 131, Cheongryang, Seoul 130-650, Korea \\ **Dept. of Chem. Eng., Yonsei University, 134 Shinchon-dong, Sudaemoon-ku, Seoul 120-749, Korea \\ (Received 4 March 2002 • accepted 29 August 2002)
}

\begin{abstract}
The conventional debinding process in metal injection molding (MIM) is critical, environmentally unfriendly and time consuming. On the other hand, supercritical debinding is thought to be an effective method appropriate for eliminating the aforementioned inconvenience in the prior art. In this paper, supercritical debinding is compared with the conventional wicking debinding process. The binder removal rates in supercritical $\mathrm{CO}_{2}$ have been measured at $333.15 \mathrm{~K}, 348.15 \mathrm{~K}$, and $358.15 \mathrm{~K}$ in the pressure range from $20 \mathrm{MPa}$ to $28 \mathrm{MPa}$. After sintering, the surface of the silver bodies were observed by using SEM. When the supercritical $\mathrm{CO}_{2}$ debinding was carried out at $348.15 \mathrm{~K}$, all the paraffin wax (71 wt $\%$ of binder mixture) was removed in 2 hours under $28 \mathrm{MPa}$ and in 2.5 hours under $25 \mathrm{MPa}$. We also studied the cosolvent effects on the binder removal rate in the supercritical $\mathrm{CO}_{2}$ debinding. It was found that the addition of non-polar cosolvent ( $n$-hexane) dramatically improves the binder removal rate (more than 2 times) for the paraffin wax-based binder system.
\end{abstract}

Key words: Supercritical $\mathrm{CO}_{2}$ Debinding, Metal Injection Molding (MIM), Binder, Diffusivity, Cosolvent

\section{INTRODUCTION}

Metal injection molding (MIM) is used to make metallic parts that cannot be readily produced by conventional material forming processes. It is a net-shape process and can be used to produce parts with complex geometries. In addition to being a cost-effective alternative for cast or forged and machined parts, MIM enables one to mass produce complex-shaped parts that are difficult to machine by conventional methods [German, 1987; Hens, 1990]. Complex shapes that are produced using the MIM process can be formed inexpensively to nearly full-density through the use of a polymer-powder combination. Because high density can be achieved, the MIM process has the ability to mould high-performance engineering materials [Tam et al., 1997]. Moreover, those parts are not necessary to any secondary machining processes. Despite the numerous advantages offered by the MIM process, several limitations exist that increase the complexity of the process. The debinding of MIM components is time-consuming and brings about defects, which affect properties of the sintered parts because of capillary force [Chartier et al., 1995], especially when the sizes of the powders used become relatively small $(<5 \mu \mathrm{m})$ [Shivashankar and German, 1999]. Furthermore, the production of a thick cross-section causes problems for the MIM process, in that the removal of the binder can be difficult.

Therefore, alternative techniques are needed to produce defectfree green bodies and to reduce debinding time. For these purposes, recently, the studies on the debinding method using supercritical $\mathrm{CO}_{2}$ are intensively investigated [Chartier et al., 1995, 1999; Shimizu et al., 1996; Milke et al., 2001; Rei et al., 2001]. The ex-

\footnotetext{
${ }^{\dagger}$ To whom correspondence should be addressed.

E-mail: limjs@kist.re.kr

This paper is dedicated to Dr. Youn Yong Lee on the occasion of his retirement from Korea Institute of Science and Technology.
}

traction of binders by supercritical fluids, which can penetrate quickly into the inside of the green metal bodies with high diffusivity and density, appears to be an interesting alternative to reduce debinding time and to avoid the creation of defects.

In this paper, supercritical debinding method is investigated and compared with conventional wicking debinding process. Wax-based binder system is used in this experiment. The binder removal rates in supercritical $\mathrm{CO}_{2}$ have been measured at $333.15 \mathrm{~K}, 348.15 \mathrm{~K}$, and $358.15 \mathrm{~K}$ in the pressure range from $20 \mathrm{MPa}$ to $28 \mathrm{MPa}$. After sintering, the surfaces of the silver bodies were observed by using SEM. We also studied the cosolvent effects (methanol, $n$-hexane) on the binder removal rate in the supercritical $\mathrm{CO}_{2}$ debinding. The diffusivities of paraffin wax in supercritical $\mathrm{CO}_{2}$ were calculated by the Fick's second law and compared with experimental data.

\section{EXPERIMENTAL}

The schematic diagram of the equipment used for supercritical debinding is shown in Fig. 1. This apparatus was designed to carry out supercritical debinding experiments in the temperature up to $373.15 \mathrm{~K}$ and pressure up to $30 \mathrm{MPa}$. The extraction vessel was made of 316 stainless steel and had an internal volume of approximately $300 \mathrm{~cm}^{3}$. In the middle part of the cell, Pyrex glass windows of $18 \mathrm{~mm}$ thickness was placed to allow visual observation of the debinding procedure. A duplex high-pressure pump (NP-D321, Nihon Seimitsukagaku Co., Ltd., JAPAN; Max. flow rate of $17.4 \mathrm{ml} / \mathrm{min}$ ) was used to feed $\mathrm{CO}_{2}$ continuously from a liquid $\mathrm{CO}_{2}$ cylinder, via a pre-heater, to the extraction vessel in which the green part (i.e., injection molded part before debinding) is loaded on a basket. A simple thermostatic air bath was used to maintain the system temperature constant within $\pm 0.5 \mathrm{~K}$. The temperature in the vessel was measured with a K-type thermocouple and a digital indicator (OMEGA Co.) which was calibrated by KRISS (Korea Insti- 


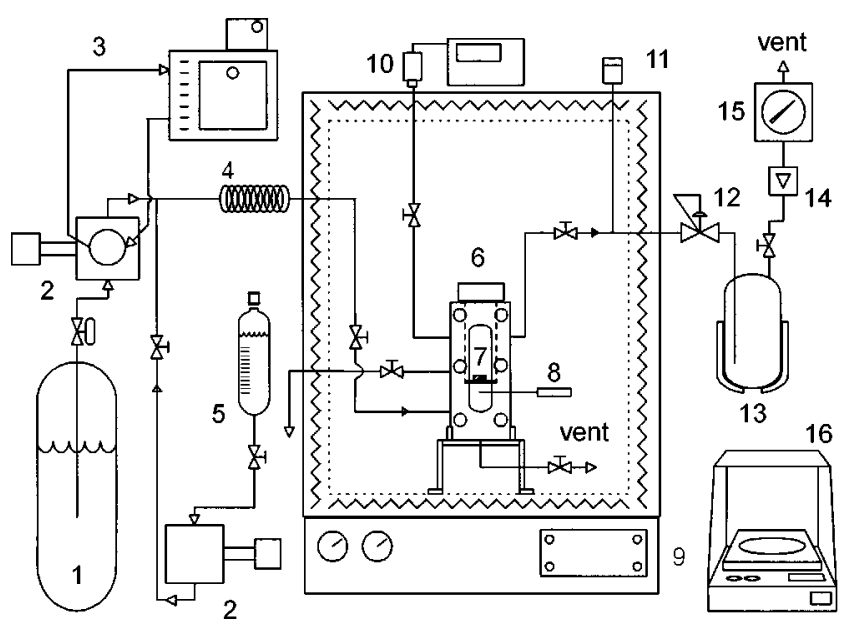

Fig. 1. A schematic diagram of the experimental apparatus.
1. $\mathrm{CO}_{2}$ cylinder
9. Air bath
2. High pressure pump
10. Pressure transducer
3. Cooling circulator
4. Pre-heater
5. Cosolvent reservoir
6 . Extraction vessel
7. Metal sample
8. Thermocouple
11. Rupture
12. Back-pressure regulator
13. Separator
14. Rotameter
15. Dry gas meter
16. Precision balance

tute of Standards and Science) with an uncertainty of $\pm 0.1 \mathrm{~K}$. The pressure in the cell was measured by a pressure transducer (SENSOTEC model TJE/0743-06TJA) and digital indicator (SENSOTEC model L20000WM1) which was calibrated by a dead weight gauge (NAGANO KEIKI PD12) with a measuring accuracy of $\pm 0.005 \mathrm{MPa}$. The system pressure was regulated within $\pm 0.05 \mathrm{MPa}$ by using a back-pressure regulator (TESCOM model 26-1722-24) which is located after the extraction vessel. The samples used in these binder removal experiments were injection molded metal green parts of $19 \mathrm{~mm}$ length, $3 \mathrm{~mm}$ thickness that is used as a milling insert. The green parts were composed of tungsten carbide- $10 \mathrm{wt} \%$ cobalt powder (of average size $1.24 \mu \mathrm{m}$ ), which were purchased from Taegu Tec. Ltd., KOREA, and binder materials (5 wt\% of the green part). The composition of the binder materials is given in Table 1. In the extraction vessel, paraffin wax contained in the green part was dissolved and extracted by the supercritical $\mathrm{CO}_{2}$. Then the sup-

Table 1. Characteristics of polymer and additives in binder $A$ and binder B

\begin{tabular}{crcc}
\hline \hline Composition (wt\%) & & $\begin{array}{c}\text { Density } \\
\left(\mathrm{g} / \mathrm{cm}^{3}\right)\end{array}$ & $\begin{array}{c}\text { Melting } \\
\text { point }(\mathrm{K})\end{array}$ \\
\hline Binder A Paraffin wax $^{a}$ & 71.3 & $0.82-0.85$ & $339.15-342.15$ \\
LDPE $^{b}$ & 23.2 & $0.90-0.94$ & $371.15-388.15$ \\
Stearic acid & 5.5 & 0.84 & $340.15-342.15$ \\
Binder B Microcrystalline wax & 71.3 & $0.84-0.87$ & $350.15-353.15$ \\
LDPE $^{b}$ & 23.2 & $0.90-0.94$ & $371.15-388.15$ \\
Stearic acid & 5.5 & 0.84 & $340.15-342.15$ \\
\hline
\end{tabular}

${ }^{a}$ Major binder: it should be removed in molded part during debinding.

${ }^{b}$ Minor binder: it should remain in molded part after debinding. ercritical fluid containing paraffin wax was expanded to atmospheric pressure after passing through the back-pressure regulator to a separator. In the separator, the paraffin wax was separated from $\mathrm{CO}_{2}$ gas and accumulated on the bottom. The amount of $\mathrm{CO}_{2}$ consumed was determined by a dry gas meter. The flow rate of $\mathrm{CO}_{2}$ gas during the experiments was fixed to $1 \mathrm{~L} / \mathrm{min}$ for all runs. In case of the experimental runs for investigating the cosolvent effects, $n$-hexane or methanol was fed to the extraction vessel by means of a high-pressure pump (NP-S-321, Nihon Seimitsukagaku Co., Ltd., JAPAN; Max. flow rate of $8.7 \mathrm{ml} / \mathrm{min}$ ). We used $n$-hexane as a non-polar cosolvent and methanol as a polar cosolvent. They were purchased from Merck chemical company and their purities were $99.8 \%$ and $100 \%$, respectively. The amount of binder removed was determined by measuring the weight of the debinded sample with a precision balance (Ohaus, model E04130). Then the brown part (i.e., injection molded part after debinding) was sintered at $1,673 \mathrm{~K}$ for $2 \mathrm{hrs}$, under vacuum conditions. After sintering, the surface of the silver part (i.e., injection molded part after debinding and sintering), such as pores and clacks, was observed by using SEM.

\section{RESULTS AND DISCUSSION}

\section{Comparison of Supercritical Debinding with Wicking De- binding}

Fig. 2 shows the extraction procedure of paraffin waxes from injection molded parts to the supercritical $\mathrm{CO}_{2}$. As can be seen in this figure, liquid wax that looks like an island appeared on the surface of the green part until 40 minutes under $25 \mathrm{MPa}, 348.15 \mathrm{~K}$, and then it dissolved gradually into solvent (supercritical $\mathrm{CO}_{2}$ ). After 1 hour, it was shown that the liquid island presented on the surface entirely disappeared. In Fig. 3, the supercritical $\mathrm{CO}_{2}$ debinding was compared with the wicking debinding, which is a conventional debinding. In this figure, the experimental data of wicking debinding was supplied by Park who works at Ceramic Processing Center in KIST. As shown in Fig. 3, wicking debinding takes more than 15 hours at high temperatures up to $723 \mathrm{~K}$. On the other hand, the supercritical $\mathrm{CO}_{2}$ debinding needs only 2 hours for the same molded part at $348 \mathrm{~K}$. Despite the fact that supercritical debinding needs an auxiliary process which is carried out in a furnace to remove the remaining polymer material in the injection molded body, it was found that the debinding time could be much more reduced compared with conventional debinding.

\section{Effect of the Solubility on Supercritical Debinding}

Fig. 4 shows the comparison of the binder removal rate of binder A (paraffin- wax based binder system) with binder B (microcrystalline-wax based binder system). As can be seen in this figure, 70.9

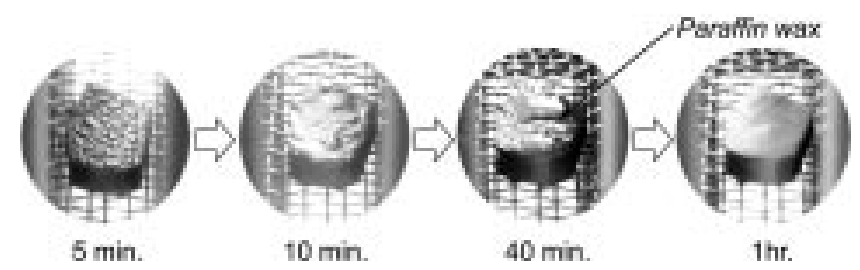

Fig. 2. The photographs for the binder removal procedure in supercritical $\mathrm{CO}_{2}$ debinding process, which were taken through the windows in extraction vessel $(T=348.15 \mathrm{~K}, P=25 \mathrm{MPa})$. 


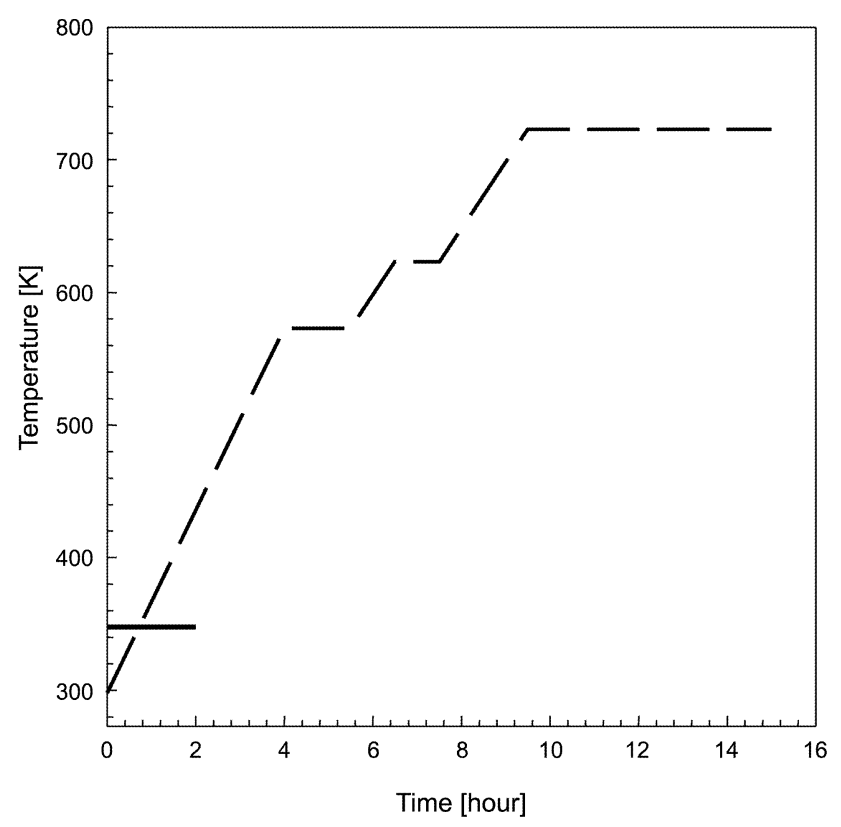

Fig. 3. Comparison of the time consumed in debinding diagram between supercritical debinding and wicking debinding : (一) supercritical debinding (28 MPa, $348.15 \mathrm{~K})$, (---) wicking debinding.

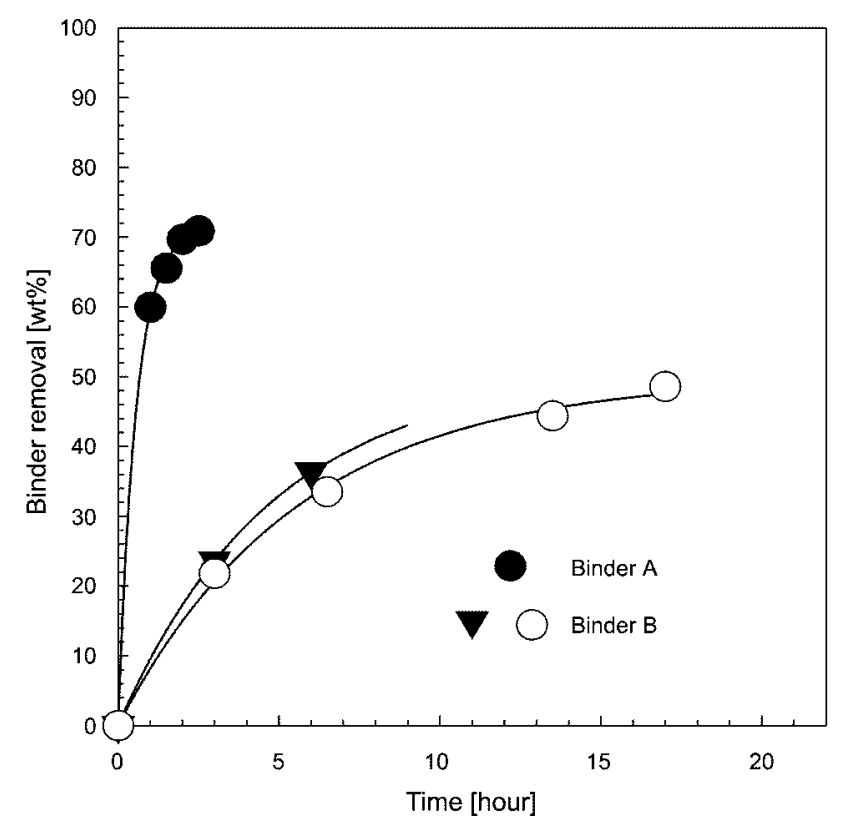

Fig. 4. Comparison of the binder removal rate of paraffin-wax based binder system (binder A) with microcrystalline-wax based binder system (binder B) at $25 \mathrm{MPa}(\mathrm{O}),(\mathrm{O}) \mathrm{T}=$ 348.15 K; ( $\nabla) \mathrm{T}=358.15 \mathrm{~K}$.

wt $\%$ of the binder (i.e., $99.4 \%$ of the paraffin wax) was removed in 2.5 hours, but microcrystalline wax was removed only $36.3 \mathrm{wt} \%$ of the binder (i.e., $51 \mathrm{wt} \%$ of the paraffin wax) in 6 hours, at above its melting point condition (350.15-353.15 K). In a related study, Takishima et al. [1991] measured the removal rate of paraffin wax and microcrystalline wax in supercritical $\mathrm{CO}_{2}$ at $343.15 \mathrm{~K}, 25 \mathrm{MPa}$. Their data showed that all the paraffin wax was removed in 2 hours, while only $20 \%$ of the microcrystalline wax was removed at the same condition. Their results were very similar to ours. These results could be interpreted by the molecular characteristics of paraffin waxes and microcrystalline waxes. Paraffin waxes consist predominantly of mixtures of straight-chain alkanes. Therefore, dispersion interactions with non-polar molecules dominate the solubility behavior [Foster et al., 1993]. In the case of microcrystalline waxes, it appears that dispersion interactions are lower than paraffin waxes, because they consist of strong-branched isoparaffins and naphthenes. For this reason, paraffin wax is much more soluble than microcrystalline wax in non-polar solvent such as supercritical $\mathrm{CO}_{2}$.

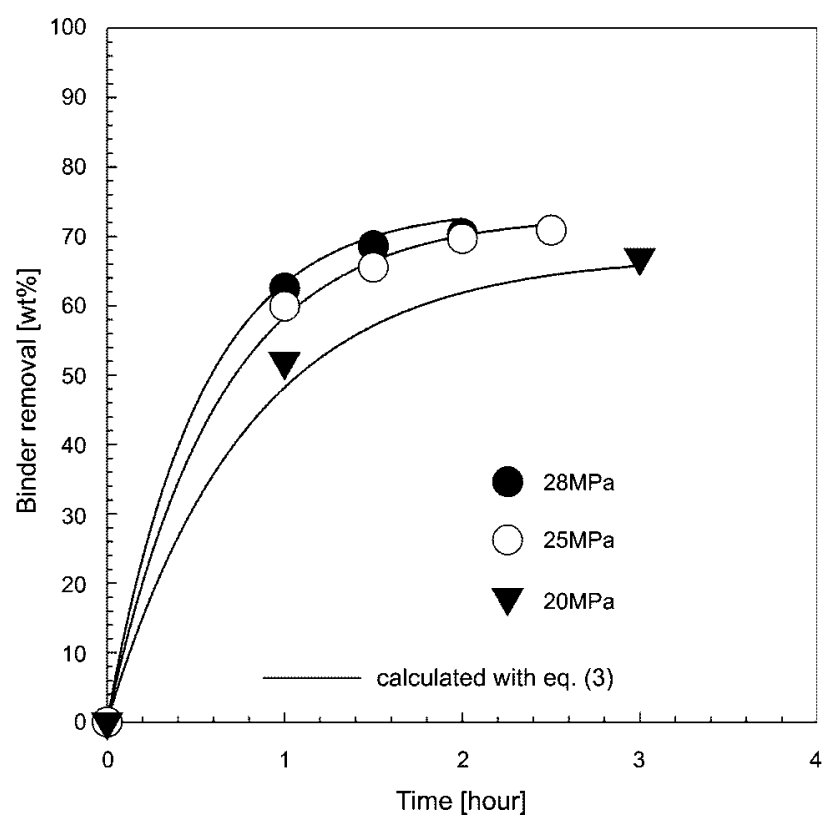

Fig. 5. Effect of the pressure on binder removal rate at constant temperature at $348.15 \mathrm{~K}$, binder A system.

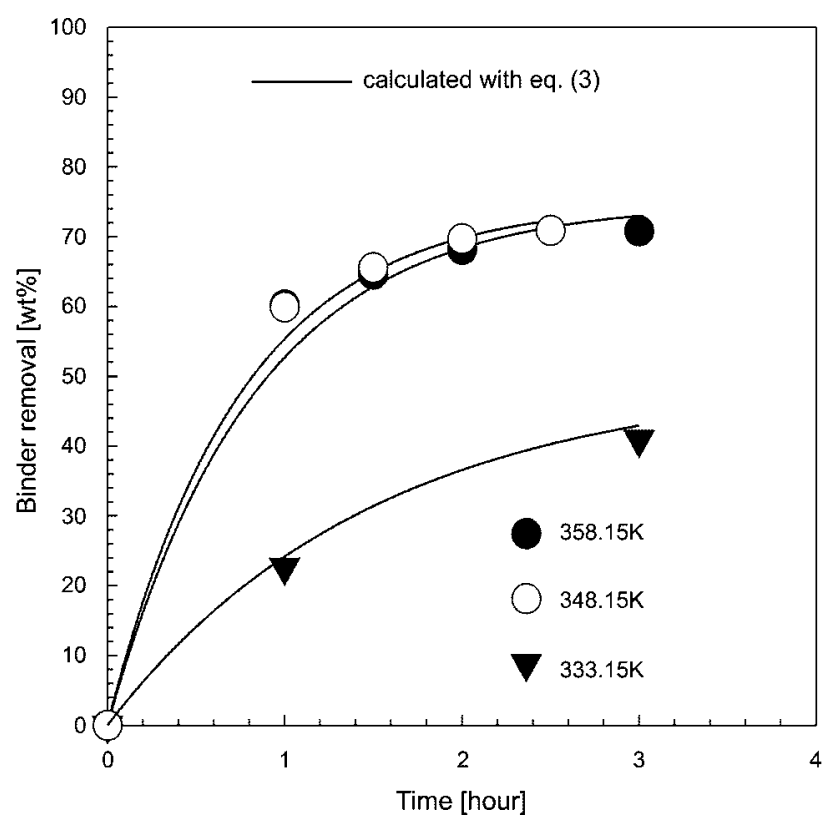

Fig. 6. Effect of the temperature on binder removal rate at 25 MPa, binder A system. 


\section{Effects of Temperature and Pressure on Supercritical De- binding}

Fig. 5 shows the effect of pressure in binder removal at same temperature. At constant temperature, the increase in pressure enhances binder removal rate. Because an increase in pressure while holding temperature results in enhancing the density of supercritical $\mathrm{CO}_{2}$, so the solubility of wax increases. For 1 hour extraction at $348.15 \mathrm{~K}$ under 20, 25 and $28 \mathrm{MPa}$, the binder removal rate was $52 \mathrm{wt} \%, 60$ $\mathrm{wt} \%$, and $63 \mathrm{wt} \%$, respectively. Fig. 6 shows the effect of temperature in binder removal at same pressure. This figure shows that debinding should be performed at a temperature higher than the melting point of used wax (paraffin wax of the melting point about 340 $\mathrm{K})$. It is important to recognize, if the debinding temperature is lower than melting point, solubility of paraffin wax decreases because paraffin wax is not whole liquid state. In the case of polymeric materials, extractions should be conducted at temperatures greater than the glass transition temperature at which the polymer free volume is increased [Taylor, 1996]. But, if the debinding temperature is higher than the melting point, as the temperature increases binder removal rate will be affected simultaneously by decreasing density of the solvent and increasing volatility of the solute. As can be seen in Fig. 6 , binder removal rate decreased as the debinding temperature increased above the melting point. From this result, it was found that binder removal rate was affected by decreasing density of the solvent (supercritical $\mathrm{CO}_{2}$ ) rather than increasing volatility of the wax.

\section{Effect of the Cosolvent on Supercritical Debinding}

One popular method of enhancing the solvent power of supercritical $\mathrm{CO}_{2}$ is adding small amount of organic cosolvent [Muthukumaran et al., 1999; Noh et al., 1995], such as methanol (polar cosolvent) or $n$-hexane (non-polar cosolvent). Fig. 7 shows the effect of cosolvent on binder removal rate in supercritical $\mathrm{CO}_{2}$. As shown in this figure, supercritical $\mathrm{CO}_{2}$ with $5 \mathrm{wt} \%$ n-hexane (increasing the non-polarity of fluid) removes $69.8 \mathrm{wt} \%$ of the binder (i.e., $98 \%$ of the paraffin wax) in 1 hour at $348.15 \mathrm{~K}, 25 \mathrm{MPa}$. But, in the case

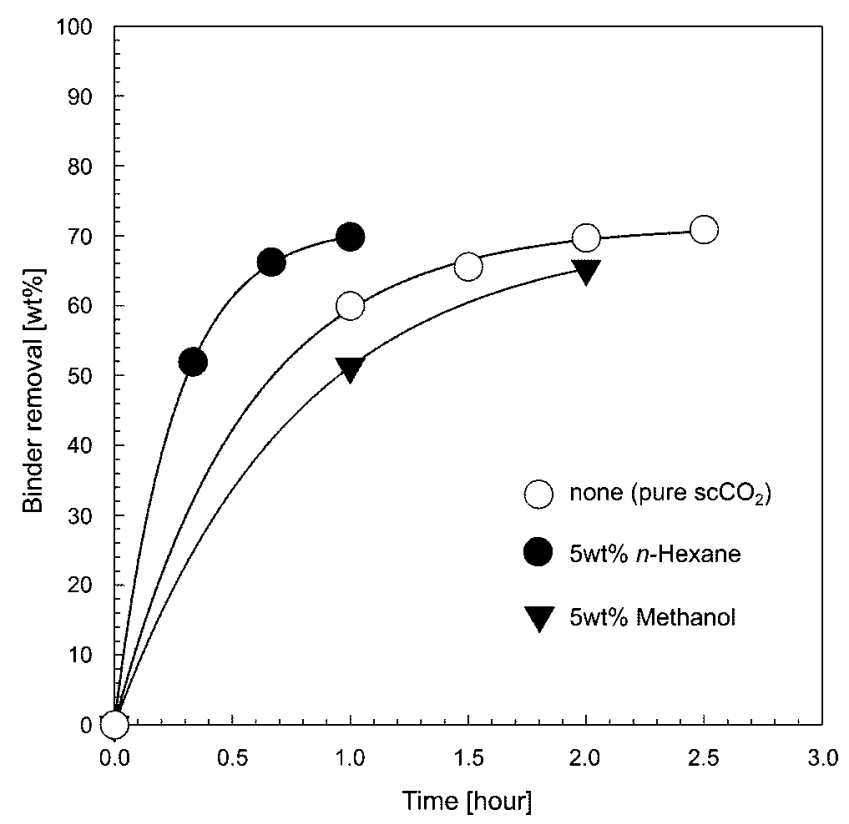

Fig. 7. Effect of the cosolvent on binder removal rate in supercritical debinding at 348.15 K, $25 \mathrm{MPa}$. of using $5 \mathrm{wt} \%$ methanol as a cosolvent (increasing the polarity of fluid), the binder removal rate was lower than using supercritical $\mathrm{CO}_{2}$ only. The paraffin wax consists predominantly of mixtures of straight-chain alkanes. The solubility behavior of paraffin wax in terms of molecular interactions will be dominated by its large hydrocarbon structure (i.e., dispersion interaction). The fact that the solubility of paraffin wax is higher in $n$-hexane than methanol indicates that the solubility of paraffin wax is affected by the dispersion interactions [Dobbs et al., 1987; Foster et al., 1993].

\section{The Evaluation of Diffusivity}

The diffusivity of a soluble wax through a porous green part was evaluated by the Fick's diffusion-based model. We assumed that green part is slab form with thickness $l$. Also, under the assumption that diffusivity of the solute is constant and diffusing solute comes out through the slab faces and a negligible amount through the edges. At first, the data analysis followed in the same manner as the procedure described by Nishikawa et al. [1991]. The diffusion of a solute can be described according to Crank [1975] and Shewmon [1963] by Eq. (1).

$$
\frac{\partial \mathrm{C}}{\partial \mathrm{t}}=\mathrm{D} \frac{\partial^{2} \mathrm{C}}{\partial \mathrm{x}^{2}}
$$

Where $\mathrm{C}$ is the solute concentration in green part and $\mathrm{D}$ is the diffusivity of the solute. The boundary conditions to be assumed are

$$
\begin{array}{lll}
\mathrm{C}=\mathrm{C}_{0} & \text { for } & 0<\mathrm{x}<l, \\
\mathrm{C}=0 & \text { for } & \mathrm{x}=l \quad \text { and } \mathrm{t}=0
\end{array}
$$

In the case of a slab, the local content of solute remaining in the green body after some time $t$ of extraction can be expressed by

$$
\mathrm{c}(\mathrm{x}, \mathrm{t})=\frac{4 \mathrm{c}_{0}}{\pi} \sum_{n=0}^{\infty} \frac{1}{2 \mathrm{n}+1} \exp \left\{\frac{-\mathrm{D}(2 \mathrm{n}+1)^{2} \pi^{2} \mathrm{t}}{l^{2}}\right\} \sin \frac{(2 \mathrm{n}+1) \pi \mathrm{x}}{l}
$$

It is often difficult to determine the concentration at various depths, and what is experimentally determined is the quantity of solute, which has been extracted, or the quantity remaining in the green part. For this purpose the average concentration $\bar{c}$ is needed, and is obtained by intergrating Eq. (2):

$$
\begin{aligned}
& \overline{\mathrm{c}}(\mathrm{t})=\frac{1}{l} \int_{0}^{l} \mathrm{c}(\mathrm{x}, \mathrm{t}) \mathrm{dx}=\frac{8 \mathrm{c}_{0}}{\pi^{2}} \sum_{n=0}^{\infty} \frac{1}{(2 \mathrm{n}+1)^{2}} \exp \left\{\frac{-\mathrm{D}(2 \mathrm{n}+1)^{2} \pi^{2} \mathrm{t}}{l^{2}}\right\} \\
& \frac{\overline{\mathrm{c}}}{\mathrm{c}_{0}}=\frac{8}{\pi^{2}} \sum_{n=0}^{\infty} \frac{1}{l^{2}} \exp \left\{\frac{-\mathrm{D}(2 \mathrm{n}+1)^{2} \pi^{2} \mathrm{t}}{l^{2}}\right\}
\end{aligned}
$$

For a long duration of supercritical debinding ( $t \gg 0)$, the first term in the right hand side of Eq. (3) shows much larger than the summation of the remaining terms, and hence, the fraction can be approximated by Eq. (4).

$$
\frac{\overline{\mathrm{c}}}{\mathrm{c}_{0}}=\frac{8}{\pi^{2}} \exp \left(\frac{-\mathrm{D} \pi^{2} \mathrm{t}}{l^{2}}\right)
$$

The values of $\mathrm{D}$ are determined by using Eq. (4) by inserting experimental values of average concentration $(\overline{\mathrm{c}})$ at time $t$ and $\ln \left(\overline{\mathrm{c}} / \mathrm{c}_{0}\right)$ plotting with time. Then the diffusivities (D) can be obtained from the slope of the plot. Table 2 shows the densities and the diffusivities determined in this work at supercritical conditions. The density of pure $\mathrm{CO}_{2}$ at a given temperature and pressure was calculated from 
Table 2. Density-diffusivity relationship for binder removal in supercritical debinding

\begin{tabular}{ccccc}
\hline \hline $\begin{array}{c}\text { Temp. } \\
(\mathrm{K})\end{array}$ & $\begin{array}{c}\text { Pressure } \\
(\mathrm{MPa})\end{array}$ & $\begin{array}{c}\text { Binder } \\
\text { removal for } \\
1 \mathrm{hr}(\mathrm{wt} \%)\end{array}$ & $\begin{array}{c}\text { Density of } \\
\text { supercritical } \\
\mathrm{CO}_{2}\left(\mathrm{~g} / \mathrm{cm}^{3}\right)\end{array}$ & $\begin{array}{c}\text { Diffusivity } \\
\left(\mathrm{m}^{2} / \mathrm{s}\right)\end{array}$ \\
\hline 348.15 & 28 & 63.44 & 0.74595 & $3.65 \times 10^{-10}$ \\
348.15 & 25 & 59.93 & 0.71292 & $2.74 \times 10^{-10}$ \\
348.15 & 20 & 51.94 & 0.62824 & $1.82 \times 10^{-10}$ \\
358.15 & 25 & 60.19 & 0.66247 & $2.24 \times 10^{-10}$ \\
333.15 & 25 & 22.64 & 0.78774 & $5.29 \times 10^{-11}$ \\
\hline
\end{tabular}

the equation of state by Angus et al. [1976]. This shows that diffusivity increases with an increase in pressure at constant temperature. Fig. 5 and Fig. 6 show that theoretical curves calculated with Eq. (3) by inserting diffusivities (D) obtained above are in good agreement with the measured data. In general, binder removal rate is affected by the diffusivity of wax, because solute diffusion will probably govern the overall rate of mass transfer. Therefore, the diffusion of supercritical $\mathrm{CO}_{2}$ might have relatively small effect on the rate of mass transfer [McHugh and Krukonis, 1994].

\section{The Analysis of the Sintered Parts Surfaces}

After debinding of the two samples--one is debinded by super-
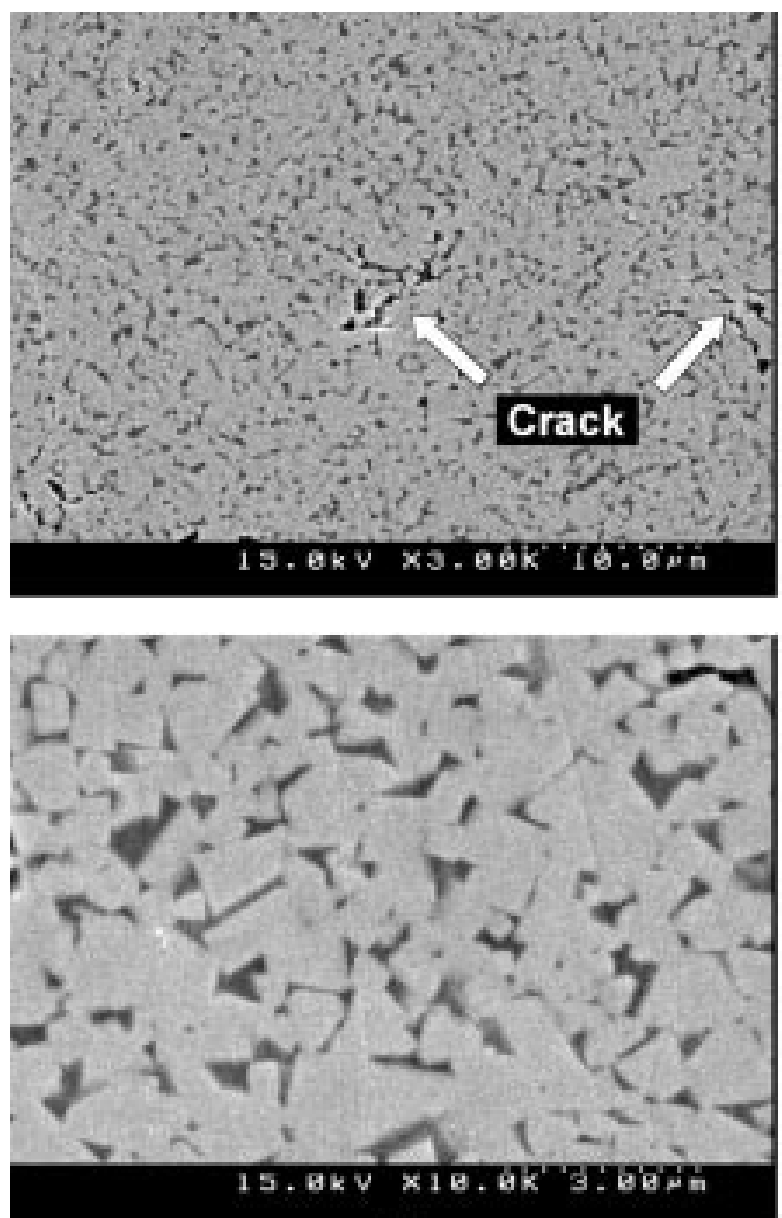

(a) critical method and the other one is by wicking method--they were sintered at $1,673 \mathrm{~K}$ for 2 hours under vacuum conditions. The micrographs of two surfaces of the silver parts are compared in Fig. 8. As can be seen in these figures, the sample from wicking debinding has a few pores or cracks but that from supercritical debinding has no defects.

\section{CONCLUSION}

In this paper, supercritical debinding is compared with conventional wicking debinding process. Wax-based binder system is used in this experiment. The binder removal rate in supercritical $\mathrm{CO}_{2}$ has been measured at $333.15 \mathrm{~K} 348.15 \mathrm{~K}$, and 358.15 in the pressure range from $20 \mathrm{MPa}$ to $28 \mathrm{MPa}$. After sintering, the surface of the silver bodies was observed by using SEM. When the supercritical $\mathrm{CO}_{2}$ debinding was carried out at $348.15 \mathrm{~K}$, almost all the wax (about $71 \mathrm{wt} \%$ of binder) was removed in 2 hours under $28 \mathrm{MPa}$, and 2.5 hrs under $25 \mathrm{MPa}$. We also studied the cosolvent effects (methanol, $n$-hexane) on the binder removal rate in the supercritical $\mathrm{CO}_{2}$ debinding. It was found that the addition of non-polar cosolvent ( $n$ hexane) dramatically improves the binder removal rate (more than 2 times) for the paraffin wax-based binder system. The diffusivities of paraffin wax in supercritical $\mathrm{CO}_{2}$ were calculated by Fick's dif-
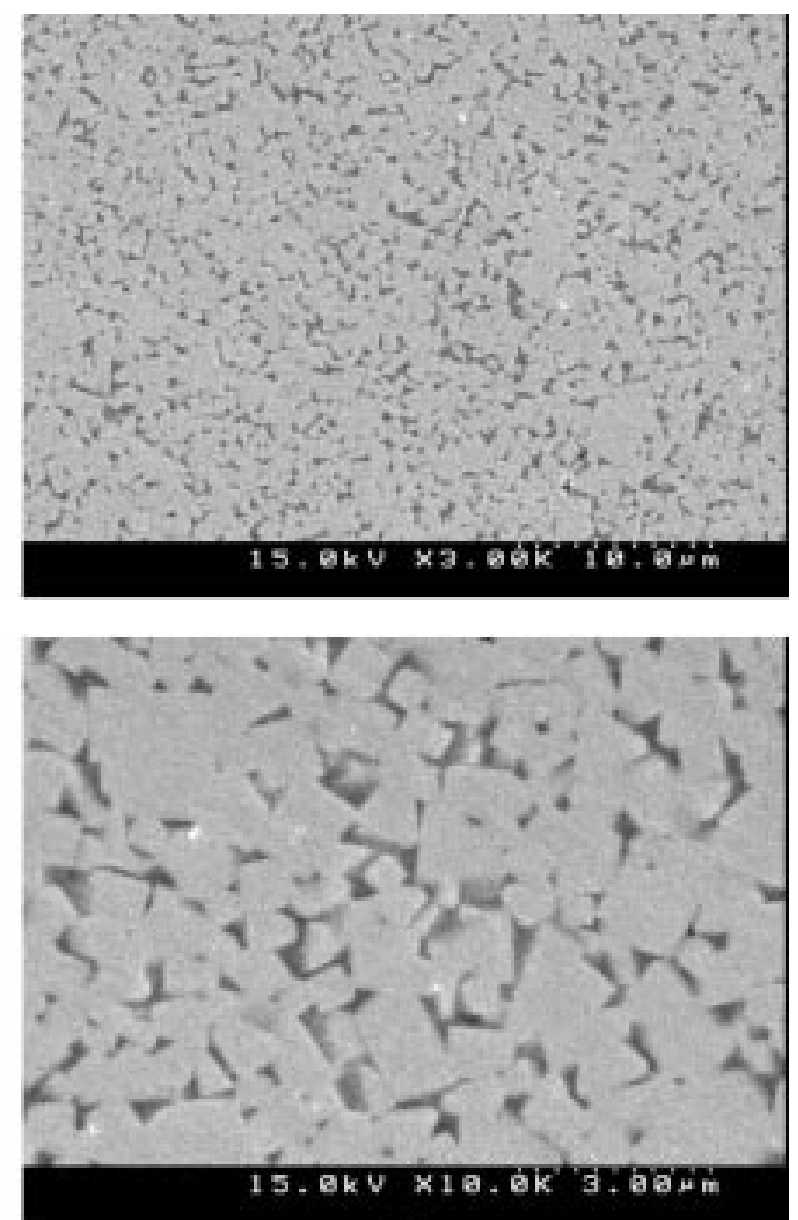

(b)

Fig. 8. SEM micrographs for the surfaces of the silver parts sintered at $1,673 \mathrm{~K}$ for $2 \mathrm{hrs}$. The silver part debinded by (a) wicking method; (b) supercritical method. 
fusion model.

In conclusion, supercritical $\mathrm{CO}_{2}$ debinding may offer a short debinding time and safe working environment as an alternative to the current conventional debinding methods, such as the solvent extraction or thermal debinding.

\section{ACKNOWLEDGMENT}

This work was supported by Ministry of Science and Technology of Korea, the National Research Laboratory Program for Supercritical Fluid. The financial contribution is greatly appreciated.

\section{REFERENCES}

Angus, S., Armstrong, A. and de Reuk, K. M., “Carbon dioxide. International Thermodynamic Tables of the Fluid State,' Pergamon, Oxford (1976).

Chartier, T., Delhomme, E., Baumard, J. F., Marteau, P., Subra, P. and Tureu, R., "Solubility, in Supercritical Carbon Dioxide, of Paraffin Waxes Used as Binders for Low-Pressure Injection Molding,' Ind. Eng. Chem. Res., 38, 1904 (1999).

Chartier, T., Ferrato, M. and Baumard, J. F., "Supercritical Debinding of Injection Molded Ceramics,' J. Am. Ceram. Soc., 78, 1787 (1995).

Chartier, T., Ferrato, M. and Baumard, J. F., "Influence of the Debinding Method on the Mechanical Properties of Plastic Formed Ceramics,' J. European Ceramic Society, 15, 899 (1995).

Crank, J., "The Mathematics of Diffusion,' 2 nd ed., Oxford University Press, Oxford (1975).

Dobbs, J. M., Wong, J. M., Lahiere, R. J. and Johnston, K. P., "Modification of Supercritical Fluid Phase Behavior Using Polar Cosolvents,' Ind. Eng. Chem. Res., 26, 56 (1987).

Foster, N. R., Singh, H., Jimmy Yun, S. L., Tomasko, D. L. and Macnaughton, S. J., "Polar and Nonpolar Cosolvent Effects on the Solubility of Cholesterol in Supercritical Fluids,' Ind. Eng. Chem. Res., 32, 2849 (1993).

German, R. M., "Theory of Thermal Debinding,' Int. J. Powder Metall., 23, 237 (1987).

Hens, K. F., "Process Analysis of Injection Molding with Powder Mixtures,' Ph.D. Thesis, Rensselaer Polytechnic Institute, New York (1990).
McHugh, M. A. and Krukonis, V. J., "Supercritical Fluid Extraction, Principles and Practice,' 2nd ed., Butterworth-Heinemann, Boston, 15 (1994).

Milke, E. C., Schaeffer, L. and Souza, J. P., "Use of Supercritical Extraction Debinding to Obtain Sintering Strontium Ferrite Magnets by Powder Injection Moulding," Advanced Powder Technology II, 636 (2001).

Muthukumaran, P., Gupta, R. B., Sung, H. D., Shim, J. J. and Bae, H. K., "Dye Solubility in Supercritical Carbon Dioxide. Effect of Hydrogen Bonding with Cosolvents,' Korean J. Chem. Eng., 16, 111 (1999).

Nishikawa, E., Wakao, N. and Nakashima, N., "Binder Removal from Ceramic Green Body in the Environment of Supercritical Carbon Dioxide with and without Entrainers,' J. Supercrit. Fluids, 4, 265 (1991).

Noh, M. J., Kim, T. G., Hong, I. K. and Yoo, K. P., "Measurements and Correlation of Effect of Cosolvents on the Solubilities of Complex Molecules in Supercritical Carbon Dioxide,' Korean J. Chem. Eng., 12, 48 (1995).

Rei, M., Souza, J. P. and Schaeffer, L., "Debinding Properties' Study of a 316-L Stainless Stell Feedstock,' Advanced Powder Technology II, 616 (2001).

Shewmon, P. G., "Diffusion in Solids,' McGraw-Hill Book Company, U.S. (1963).

Shivashankar, T. S. and German, R. M., "Effective Length Scale for Predicting Solvent-Debinding Times of Components Produced by Powder Injection Molding,' J. Am. Ceram. Soc., 82, 1146 (1999).

Shimizu, T., Mochizuki, S., Sano, T. and Fuchizawa, S., "Supercritical $\mathrm{CO}_{2}$ Debinding Method in MIM Process-Debinding Condition and Process in Supercritical Debinding-,' P. P. Metall. (in Japanese), 43, 1188 (1996).

Takishima, S., Matsumoto, H., Nagasaki, H., Masuoka, H., Mukai, Y. and Sakai, Y., (in Japanese), "Debindering from Alumina Green Body by Supercritical Carbon Dioxide,' Kagaku Kogaku Robunshi, 17, 243 (1991).

Taylor, L. T., "Supercritical Fluid Extraction,' John Wiley \& Sons, Inc. (1996).

Tam, K. C.,Yap, S. P., Foong, M. L. and Loh, N. H., "Metal Injection Molding: Effects of the Vinyl Acetate Content on Binder Behavior,' J. Mater. Process. Tech., 67, 120 (1997). 